\title{
Promoção da saúde na comunidade indígena Pankararu
}

\author{
Health promotion in the Pankararu indigenous community \\ Promoción de la salud en la comunidad indígena Pankararu
}

\section{Jonas Welton Barros Oliveira', Jael Maria Aquino", Estela Maria Leite Meirelles Monteiro"}

\author{
' Universidade de Pernambuco, Faculdade de Enfermagem Nossa Senhora das Graças, \\ Programa Associado de Pós-graduação em Enfermagem UPE/UEPB (Pós-graduando), Grupo de Estudos e Pesquisas \\ em Epistemologia e Fundamentos do Cuidar. Recife-PE, Brasil. \\ "Universidade de Pernambuco, Faculdade de Enfermagem Nossa Senhora das Graças, \\ Programa Associado de Pós-graduação em Enfermagem UPE/UEPB, Grupo de Estudos e Pesquisa \\ em Epistemologia e Fundamentos do Cuidar em Saúde e Enfermagem. Recife-PE, Brasil.
}

Submissão: 04-03-2010 Aprovação: 25-07-2012

\section{RESUMO}

O objetivo do estudo foi conhecer como os indígenas Pankararu percebem sua situação de saúde, e identificar que ações priorizam como necessárias para a promoção da saúde em sua comunidade. Pesquisa qualitativa. Os depoimentos coletados foram submetidos à técnica de análise do Discurso do Sujeito Coletivo. Na percepção dos indígenas, quanto à situação de saúde de sua comunidade, foi ressaltado uma carência de assistência geral e falta de profissionais para atender conforme suas necessidades. Em relação às ações que os indígenas priorizam como necessárias para a promoção à saúde da comunidade foram destacadas a oferta de postos de saúde com profissionais capacitados e o acesso às ações de educação em saúde. Foi proposta uma reformulação das organizações e estabelecimentos dos subsistemas na promoção à saúde indígena.

Descritores: Promoção à Saúde; Educação em Saúde; Indígenas.

\section{ABSTRACT}

The objective of the study was to know how the Pankararu indigenous perceive their health situation and identify actions they prioritize as necessary to promote health in their community. Qualitative research, in which the declarations collected were subjected to the technique of analyzing the Collective Subject Discourse. It was identified that in the indigenous perception, as the health status of their community, there is a lack of general assistance, and a lack of professionals to assist them meeting their needs. In relation to actions that the Indigenous prioritize as necessary to promote the health of their community, it was highlighted provision of health unit with trained professionals and access to health education actions. It was, thus, proposed an overhaul of the organizations and establishments of the subsystems in promoting indigenous health.

Key words: Health Promotion; Health Education; Indigenous.

\section{RESUMEN}

El estudio tuvo como objetivo conocer como los Indígenas Pankararu perciben su situación de salud e identificar que acciones de salud ellos priorizan como necesarias para la promoción de la salud de su comunidad. Investigación con abordaje cualitativo. Las declaraciones colectadas fueron sometidas a la técnica de análisis del Discurso del Sujeto Colectivo. Fue identificado en la percepción de los indígenas, en relación a la situación de salud de su comunidad, la falta de asistencia general y la falta de profesionales para atender de acuerdo con las necesidades de los indios. En relación a las acciones que los indígenas priorizan como necesarias para promover la salud de su comunidad se pusieron de relieve, la provisión de puestos con profesionales capacitados y el acceso a las acciones de educación en salud. Así pues, se propuso una reforma de las organizaciones y establecimientos de los subsistemas en la promoción de la salud indígena.

Palabras clave: Promoción de la Salud; Educación en Salud; Indígenas. 


\section{INTRODUÇÃO}

No Brasil, na década de 1970, o modelo teórico da saúde coletiva surgia, organizando-se, dessa forma, o Movimento Sanitário que propôs a estruturação da atenção através do histórico social e estudo epidemiológico, apontando novos métodos de análise que questionassem as ações de prevenção e controle das doenças, desconsiderando as relações sociais de exploração(1).

No âmbito mundial, surge a promoção da saúde moderna, com a publicação do Relatório Lalonde, no Canadá, em 1974, cujo eixo principal indicava a necessidade de formar meios de intervenções que transformassem os comportamentos individuais não saudáveis. Nas duas últimas décadas do século XX, emergiu a corrente da nova Promoção à Saúde, com referencial na Carta de Ottawa, enfatizando os determinantes socioambientais na explicação do processo saúde-doença ${ }^{(2)}$.

No Brasil a promoção da saúde começou a ganhar força na década de 1990, com presente influência do pensamento sanitário, modificando o atual modelo teórico de vigilância à saúde, determinando novas diretrizes como a das cidades saudáveis e o programa de saúde da família(2).

A promoção da saúde requer um conjunto de atividades, processos e recursos de ordem institucional, governamental ou da cidadania, orientado a propiciar o melhoramento de condições de bem estar e acesso a bens e serviços sociais que favoreçam o desenvolvimento de estratégias que possibilitem à população um maior controle sobre sua saúde e suas condições de vida no níveis individual e coletivo ${ }^{(3)}$.

Neste sentido, é imprescindível que estudos sobre desigualdades socioeconômicas, e aqueles concernentes ao processo saúde-doença, tanto no Brasil como na América Latina em geral incorporem cada vez mais as variáveis raça/etnia como dimensões analíticas ${ }^{(4)}$. A desvantagem econômica e social seria um dos mecanismos através do qual a discriminação contribui para as desigualdades étnico/raciais de saúde ${ }^{(5)}$.

Nove anos após a criação do SUS, o Decreto $\mathrm{n}^{\circ} 3.156^{(6)} \mathrm{e} \mathrm{a}$ Lei $n^{\circ} 9.836^{(7)}$ determinaram as condições de assistência à saúde dos povos indígenas e o Subsistema de Atenção à Saúde Indígena no âmbito do SUS, respectivamente, tendo em vista as históricas desigualdades e iniquidades vividas por esses povos no Brasil. Posteriormente, essa legislação regulamentou a Política Nacional de Atenção à Saúde dos Povos Indígenas (PNASPI), integrante da Política Nacional de Saúde ${ }^{(7)}$.

Neste cenário, emerge a importância dos profissionais de saúde para o desenvolvimento de uma metodologia de trabalho que busque a promoção da saúde das comunidades indígenas, respeitando sua organização cultural e religiosa, procurando articular saberes técnicos com os saberes tradicionais da comunidade, desenvolvendo, nesse grupo, valores relacionados com a qualidade de vida. Constituem, assim, exemplos de valores à saúde, à equidade, o desenvolvimento, à participação e a parceria, ao fomentar um sistema de saúde comprometido com a promoção da saúde da comunidade indígena.

Os problemas sociais e políticos vivenciados pela população indígena, com repercussão na mídia nacional e internacional, e, em particular, as questões referentes à situação de saúde, contribuem para a inquietação dos autores deste estudo na busca de aprofundar os conhecimentos sobre essa realidade e de ampliar as discussões no cenário acadêmico que envolvem o direito à saúde desta população em situação de vulnerabilidade. É evidenciada, portanto, uma influência multifatorial, resultante das especificidades como modo de vida, clima, dimensão geográfica, pobreza, nível educacional(8).

Diante do exposto, o estudo tem como objetivos os de conhecer como os indígenas Pankararu percebem sua situação de saúde; e identificar que ações de saúde os indígenas priorizam como necessárias para a promoção da saúde de sua comunidade.

\section{METODOLOGIA}

Diante da natureza deste estudo, optou-se por uma pesquisa descritiva, exploratória, com abordagem qualitativa. O estudo foi realizado na tribo Pankararu, que está localizada entre os atuais municípios de Petrolândia, Jatobá e Tacaratu, no sertão pernambucano onde ocupam uma área de terra de 14.290 hectares. Essa comunidade indígena, a exemplo de outras, vem sofrendo há mais de 500 anos influência e domínio da sociedade constituída por um pensamento colonizador domesticador, comprometido com a formação de casta, manutenção do status quo e do poder hegemônico ${ }^{(9)}$.

O eixo central dessas terras é a aldeia Brejo dos Padres, circundada por mais doze comunidades que, juntas, têm aproximadamente seis mil índios. A composição dos participantes do estudo foi estabelecida por amostra intencional, sendo definida por índios e índias da Comunidade Pankararu com idade superior a 21 anos, escolhidos em função da relevância que eles apresentam em relação às questões que envolvem a promoção da saúde em sua comunidade.

Como critério de intencionalidade, foi considerada a identificação dos indígenas que desenvolvem uma atuação de liderança entre os Pankararu, visto que estes são reconhecidos pelos seus pares como representantes nas discussões que envolvem os seus interesses e suas necessidades, apresentando uma maior liberdade de expressão. A participação de integrantes indígenas da população feminina neste estudo é respaldada no papel que elas vêm assumindo na discussão das políticas de atenção à saúde em geral, com destaque para as especificidades que envolvem as questões de gênero.

A coleta foi realizada nos meses de julho e agosto de 2008, mediante a utilização de um roteiro de entrevista com duas questões abertas, além de dados de caracterização do grupo. As falas foram registradas na íntegra, sendo procedida a leitura do discurso apreendido para apreciação do entrevistado. Entretanto, foi respeitado o desejo de alguns indígenas que optaram por se expressar através da escrita. Todo o material coletado foi submetido a sucessivas leituras e posterior pré-análise, com exploração das falas, tratamento dos resultados e interpretação.

Para o desenvolvimento da investigação, foi necessário obter anuência formal de autoridade máxima da tribo, como também das instituições reconhecidas como representantes das comunidades indígenas no Estado.

Participaram do estudo 25 indígenas, que foram selecionados respeitando a representatividade de ambos os gêneros e 
o papel de liderança que os mesmos exercem no grupo, com indicação de agentes de saúde e moradores da comunidade. As entrevistas aconteceram na residência dos entrevistados.

A técnica do Discurso do Sujeito Coletivo estabeleceu uma organização de dados discursivos em pesquisa qualitativa, proporcionando resgatar a fala dos indígenas sobre as condições de saúde, e as ações necessárias para promoção da saúde de sua comunidade. Os discursos, depois de transcritos, foram submetidos a uma análise de conteúdo, sendo os mesmos decompostos individualmente nas principais Ancoragens ou Idéias Centrais, reunidos e sintetizados visando à constituição discursiva da representação social(10).

Para desenvolvimento do estudo foram respeitadas as exigências legais e éticas determinadas pela Resolução $n^{\circ}$ 304/2000 do Conselho Nacional de Saúde, que complementa a Resolução 196/96, no que diz respeito à área temática especial "populações indígenas"(11). A autorização para desenvolvimento deste estudo deu-se através do Protocolo n 92/08 e CAAE no 0089.0.097.00-08, emitido pelo Comitê de Ética em Pesquisa da Universidade de Pernambuco.

\section{RESULTADOS}

\section{Caracterização dos sujeitos}

Dos vinte e cinco indígenas participantes do estudo, todos residiam na comunidade indígena Pankararu, sete do sexo feminino, treze do sexo masculino, ambos estavam na faixa entre 21 e 70 anos, vinte eram casados; cinco solteiros.

Quanto ao nível de escolaridade dos depoentes, dois cursaram o ensino fundamental I; três estudaram até o fundamental II; dez até o ensino médio, seis estavam concluindo o ensino médio, dois haviam cursado o ensino superior completo e dois o superior incompleto. A renda familiar variou entre um e três salários mínimos. A grande maioria trabalha na agropecuária sazonal. Os indígenas com curso superior completo atuam como professores na própria comunidade e os demais exercem uma das seguintes profissões: merendeiras, agentes de saúde, auxiliar de serviços gerais, motorista e vigia. É importante ressaltar o papel de liderança exercido dentro da comunidade por alguns dos entrevistados.

Os resultados foram apresentados em duas Ideias Centrais: Percepção dos indígenas quanto à situação de saúde de sua comunidade e as ações que os mesmos priorizam como necessárias para a promoção à saúde, acompanhadas dos Discursos do Sujeito Coletivo correspondentes. Os mesmos foram elaborados com os conteúdos manifestados nas Expressões Chaves citadas de um ou mais discursos concretos.

IDEIA CENTRAL I - Percepção dos indígenas quanto à situação de saúde de sua comunidade

Nesta ideia central foi evidenciada a percepção dos indígenas quanto à situação de saúde de sua comunidade, subsidiando a identificação de dois temas: um com ênfase na carência de assistência de um modo geral, e outro destacando o despreparo de profissionais para atender conforme as necessidades dos indígenas.

\section{Tema A - Falta assistência geral}

Discurso do Sujeito Coletivo: (...) Acho que o povo anda adoecendo mais, (...) esse tempo é tanta doença que a gente não sabe nem o nome (...) não tem nada bom, pessoas morrendo sem o devido atendimento, os agentes não visitam os doentes. Quando o atendimento era por Paulo Afonso, cidade do interior da Bahia, era melhor (...). Os remédios químicos não são repassados com freqüência, falta passagem de ônibus para as pessoas. Médicos ausentes da comunidade onde precisa ir até a cidade vizinha. Só sobrevive quem tem um recurso próprio (...) falta assistência geral, tem que depender da sorte (...) tem que se virar com remédio do mato mesmo, o dentista também sempre tá faltando material, então a comunidade vem sofrendo muito (...). Os índios morrem nos corredores dos hospitais por falta de vaga para internação, quando um índio consegue começar o tratamento, demora tanto vir o chamado que muitas vezes quando é chamado para consulta ou exame, o caso não tem mais jeito (...). A propaganda é bonita, mas vivemos jogados nos hospitais municipais e estaduais..

Os discursos acima evidenciaram que há pouca resolutividade e total descontinuidade nas ações de atenção à saúde, acesso aos serviços básicos e programas de promoção à saúde que privilegiem e aproximem mais as comunidades indígenas Pankararu das esferas que compõem o Serviço Único de Saúde (SUS). Não se observa uma assistência humanizada, permanente, e, sobretudo, mais resolutiva que coloque em pauta princípios como territorialidade, vínculo dos profissionais com a comunidade, continuidade e integralidade das ações de saúde, planejamento local, controle social e promoção à saúde em seu real significado.

Foi relatada uma carência no acesso às informações acerca das patologias que prevalecem na comunidade, modos de contágio e/ou fatores desencadeantes, medidas de prevenção e tratamento, ocorrendo uma lacuna na realização de atividades de educação em saúde. Os discursos evidenciaram ainda, o desrespeito nas ações que envolvem, direta ou indiretamente, a assistência farmacêutica na atenção à saúde indígena Pankararu, tais como controle, programação, seleção, aquisição, prescrição e distribuição, devido à escassez de medicamentos essenciais no tratamento de doenças crônicas, causando total indignação e sentimento de abandono por parte daqueles que necessitam da medicação diariamente.

Foi constatada nos discursos uma desarticulação no desenvolvimento de práticas de promoção que instruísse o uso racional dos medicamentos essenciais, respeitando e valorizando as práticas tradicionais de cura. Visto que, historicamente, prevalecem os conhecimentos e as terapêuticas naturais na população indígena, que são utilizadas de forma complementar ou totais, considerando o conceito de saúde e o processo de adoecer na percepção da cultura indígena, que difere dos princípios que embasam a medicina ocidental.

A promoção da saúde na comunidade indígena Pankararu necessita do desenvolvimento de ações integradas e articuladas ao comportamento dos mesmos, focando em seu ambiente 
cultural diferenciado, seu estilo de vida e a relação entre eles e o meio ambiente. Neste caso, os programas ou atividades de promoção da saúde tendem a concentrar-se em componentes educativos, que propiciem a disseminação de conhecimento científico articulado ao saber popular, instrumentalizando os profissionais de saúde e a população na identificação e priorização dos problemas de saúde, como também no levantamento de propostas para sua resolutividade.

Desse modo, a promoção da saúde configura-se como estratégia de mudança nos modelos tecnoassistenciais, sinalizando a construção de outras possibilidades e a configuração de novos saberes e fazeres que ampliem as alternativas de qualidade de saúde e vida ${ }^{(12)}$ na comunidade Pankararu.

O entendimento amplo de saúde vem redirecionar o agir sanitário, favorecendo o estabelecimento de uma rede de compromissos em favor da vida e da criação de estratégias de mobilização para a consolidação de comportamentos saudáveis dentro das aldeias, como também, na reivindicação de direitos que venham propiciar mudanças na realidade posta.

Tema B - Faltam profissionais para atender conforme as necessidades dos índios

Discurso do Sujeito Coletivo: (...) A situação é que falta mais atenção pra saúde dos índios daqui (...). Só quando fica mal mesmo é que procura uma ajuda. Se tivesse um atendimento diário e organizado a pessoa cuidava da doença logo que ela chegasse ou até antes, porque o que falta é isso, informação pra o pessoal ficar sabendo o que tem e o que não tem e como evitar né (...). Faltam mais profissionais pra atender conforme as necessidades dos índios, além de incoerência nas relações culturais de profissionais de saúde, que atuam com povo indígena (...). Antes de mais nada, deveria tentar entender seus costumes, cultura, dessa forma, o trabalho desse profissional ganharia mais eficácia, pois estaria ele entendendo melhor a linguagem daqueles aos quais ele presta o serviço(...).

Foi evidenciado, nos discursos, um descontentamento com os serviços de atenção à saúde nas áreas indígenas, identificando uma dicotomia entre as propostas legais e assistência posta nas comunidades. A atenção à saúde na comunidade é caracterizada por um desrespeito à construção de uma atenção integral e equânime à saúde Pankararu, o que impossibilita a implementação de um modelo de atenção específico e diferenciado.

$\mathrm{Na}$ atual conjuntura em que se vivência a saúde indígena Pankararu, ainda não foi possível haver uma otimização entre o arcabouço legal que resgarda os direitos de cidadania em saúde dos povos indígenas e as políticas públicas instituídas pelo setor saúde, desenvolvidas pela Fundação Nacional de Saúde (FUNASA), órgão federal responsável por prestar assistência à saúde aos povos indígenas e cadastrá-los no Sistema de Informação da Atenção à Saúde Indígena (Siasi)(6).

Assim, entende-se que é urgente superar a cultura administrativa fragmentada e desfocada dos interesses e das necessidades do grupo indígena pesquisado, sendo constatada a redução e superposição de atividades, que comprometem a efetividade das ações de saúde existentes, resultando num sentimento de total desassistência por parte dos índios entrevistados.

Os discursos apontam uma desestruturação nas ações de saúde aos grupos indígenas, que continuam marcadas por um modelo de atenção ainda hospitalocêntrico, centrado na doença, dissonante dos princípios norteadores do SUS, com desperdício de recursos públicos, com formas ineficazes no atendimento das necessidades da população, como também, desvinculadas de uma leitura da realidade de saúde dos indígenas Pankararu.

O subsistema em saúde indígena desenvolvido em Pankararu apresenta falha no planejamento das ações em saúde, pois apesar da participação das lideranças, mediante os Conselhos Distritais de Saúde, suas reivindicações não são consideradas, o que caracteriza uma participação apenas simbólica e não um exercício de cidadania no controle social das ações de saúde propostas para a comunidade.

Os profissionais não conseguem estabelecer um vínculo com a comunidade, pela dificuldade de identificar as necessidades vivenciadas pelos indígenas, concomitantemente, não garante a sustentabilidade dos processos de intervenção nos determinantes e condicionantes de saúde que deveriam estar aliados à Política Nacional de Promoção da Saúde.

Foi evidenciada no discurso, a necessidade de uma relação de proximidade e confiança dos profissionais prestadores de serviço em saúde com a comunidade indígena. As dificuldades em estabelecer uma interação entre os protagonistas no cenário da saúde indígena constituem uma barreira no desenvolvimento de ações de promoção à saúde.

Essas dificuldades ocorrem, entre outras causas, por não serem consideradas as especificidades que envolvem os grupos tribais Pankararu, principalmente por estes se encontrarem em situação de transculturação. Na área de saúde, a transculturação pode ser observada de duas formas: de um lado, a medicina exercida pelos profissionais de saúde com embasamento técnico científico que diagnosticam, previnem e tratam doenças, visando manter o bem-estar individual e coletivo; do outro lado, a medicina dos pajés e seus saberes e práticas culturais de cura espiritual que transcendem o cuidado biomédico, na relação dos homens com a natureza e a espiritualidade.

Todos os modos oriundos da medicina popular de explicar, diagnosticar e tratar os problemas que envolviam a saúde dos indivíduos foram relegados pela medicina moderna ao plano do esoterismo, da irracionalidade, do ilógico, reconhecidos, portanto, como impróprios à missão de proporcionar o bem-estar do homem que necessitava de cuidados. É, ainda, nessa perspectiva que muitos profissionais de saúde percebem e rotulam tais sistemas de conhecimentos sobre a saúde e a doença $a^{(13)}$.

No entanto, a Antropologia da Saúde e da Doença tem mostrado, por meio de seus estudos, o engano de tais classificações que na verdade desconhecem o sistema lógico dessas formas de saber; que, porém, só fazem sentido no contexto onde são elaborados, manipulados e interpretados ${ }^{(14)}$.

O reconhecimento e valorização do saber dos curandeiros, 
líderes espirituais da tribo, é essencial para uma articulação entre os saberes popular e científico, com adesão aos serviços e as ações de promoção à saúde. É enfatizado o desejo de que não apenas ocorra a simples transferência de conhecimentos biomédicos, mas a sua articulação com os sistemas tradicionais de cura, que venham integrar a figura dos especialistas indígenas das práticas tradicionais, respeitando suas singularidades e especificidades no processo saúde-doença, considerando as relações entre os indivíduos, seu meio ambiente e rituais espirituais nas ações de promoção a saúde.

Emerge a necessidade do reconhecimento pelos profissionais de saúde, da influência que os líderes espirituais exercem dentro da comunidade, como provedores responsáveis pela saúde na aldeia.

A tolerância das duas práticas é de fundamental importância, para que os profissionais de saúde, índios e não índios consigam elucidar a concepção indígena no processo saúde-doença que no momento atual não agrega a multiplicidade de saberes com as características culturais do grupo estudado, desrespeitando suas concepções em relação a tabus, linguagens e símbolos que deveriam ser contemplados na construção das propostas de ações de promoção à saúde com essas comunidades.

São evidenciados a intolerância e o desrespeito de profissionais de saúde ao estabelecerem uma relação autoritária, e, sobretudo, de ignorância com relação às medicinas indígenas. Muitos profissionais manifestam atitudes preconceituosas no exercício de suas atividades de prevenção e cura, ao caracterizar esses povos como sujos, ignorantes quanto às questões de saúde, além de resistentes ao tratamento pela sua incapacidade de compreendê-los ${ }^{(9)}$. Estudos com a população indígena têm revelado que, as intervenções na área de saúde são realizadas sem o devido respeito para o conhecimento da cultura do grupo, e, assim, os profissionais expressam atitudes etnocêntricas e realizam suas práticas sem reconhecer como a especificidade cultural do grupo influencia no êxito de seu trabalho ${ }^{(9)}$.

Dessa forma, é percebido que o modelo atual não contempla e não promove a articulação entre os sistemas tradicionais de curas que se apresentam como um dos principais, se não o principal recurso de atenção à saúde na comunidade indígena Pankararu. Para que essa proposta de integração preconizada nos documentos propostos pelas Conferências e pelas Políticas de Atenção à Saúde Indígena seja incorporada dentro das comunidades, é essencial realizar ações conjuntas e intersetoriais na construção coletiva de saberes, linguagens e práticas, entre os diversos setores envolvidos na elaboração, implementação e avaliação da assistência realizada para esse grupo populacional, na tentativa de produzir soluções inovadoras quanto à melhoria de sua qualidade de vida(15).

Entretanto, essa tão esperada reordenação da rede de saúde está ainda muito distanciada de contemplar uma ação inclusiva e participativa, com ênfase no controle social. Visto que os discursos anunciam a falta de capacitação adequada para os agentes indígenas de saúde (AIS), a carência de enfermeiros, médicos e farmacêuticos no desenvolvimento de ações educativas no sentido de garantir a adesão dos indígenas aos tratamentos; e ainda a carência de estudos clínicos, epidemiológicos e antropológicos específicos que contemplem as necessidades desses povos.

As ações de saúde junto a este grupo étnico deveriam estar articuladas e organizadas no sentido de produzirem um efeito sobre a saúde no plano coletivo, não se oferecendo apenas um atendimento médico ambulatorial com métodos paliativos que resolvem problemas momentâneos, mas sim ampliando a oferta de ações de caráter preventivo.

\section{IDÉIA CENTRAL II - Ações que os indígenas priori- zam como necessárias para a promoção à saúde de sua comunidade.}

Tema A - Posto com profissionais de saúde.

Discurso do Sujeito Coletivo: (...) Precisava primeiro de um posto que tivesse médico, pra atender o povo todo dia quando precisasse (...), que não demorasse tanto pra gente receber o resultado porque acaba é piorando sem saber o que tem (...). Buscar convênios com clínicas mais próximas à área indígena para casos de atendimento fora da área (exames, cirurgias simples, etc.), evitando o deslocamento pra capital, principalmente dos mais idosos (...); contratação de médico, dentista, enfermeiro (dispostos a trabalhar) para atendimento diário de oito horas dia, durante a semana, assim trabalhariam exclusivamente dentro da área (...) só assim todos indígenas teriam um atendimento, somente sendo enviados à capital casos graves (...), pois as pessoas vão arriscando a vida nas estradas (...); acompanhamento integral dos doentes que tem hipertensão e doença do coração, respeito no repasse de remédios, melhor acompanhamento da FUNASA Recife, porque teve um parente que passou dezessete dias no corredor do hospital Getúlio Vargas e disse que ninguém da FUNASA apareceu (...).

As declarações colocam em discussão os limites e perspectivas de implementação de políticas públicas e práticas de promoção e vigilância à saúde articuladas às demandas e necessidades peculiares à comunidade indígena, sendo evidenciada nos discursos uma prática de saúde desvinculada das propostas do SUS, ainda com restrições de acessibilidade, voltadas a práticas curativas.

O sistema de saúde vigente enfatiza o processo de regionalização, através da instalação dos Distritos Sanitários Especiais Indígenas. Os modelos tecnoassistenciais da Vigilância da Saúde e em Defesa da Vida, propõem acolhimento, vínculo, busca da autonomia e a gestão participativa, como formas de governar processos de trabalho, na busca da qualidade de vida dos cidadãos usuários do sistema ${ }^{(16)}$. Entretanto, os discursos apontam para um distanciamento entre as propostas regulamentadas e os modos de atenção à saúde disponibilizados à população indígena de Pankararu.

Os modelos de atenção à saúde constituem formas de organização das relações entre os profissionais de saúde e os usuários, mediadas por tecnologias (materiais e não materiais) necessárias ao processo de trabalho em saúde, cujo propósito 
é intervir sobre os danos, riscos e necessidades sociais de saúde historicamente definidos ${ }^{(3)}$.

Desse modo, é evidenciada a necessidade de se distinguir, a elaboração de propostas políticas e estratégicas que objetivem a introdução de mudanças no sistema de saúde, identificando os desafios que se colocam na conjuntura atual para que o processo de redefinição das políticas de atenção à saúde indígena e reorganização dos serviços em nível local, levem em conta, não apenas as necessidades de se garantir a integralidade do cuidado, mas também a equidade na distribuição social das ações e serviços voltados a saúde da população indígena Pankararu.

Faze-se necessário o debate acerca dos processos, resultados e perspectivas da atenção à saúde nas comunidades indígenas Pankararu, no intuito de entender como se apresentam e qual a resolubilidade das estratégias de descentralização e regionalização dos serviços, buscando alternativas de ação que possam contribuir para o alcance ou a aproximação dos objetivos que propõem as diretrizes do SUS em relação a essas comunidades.

Tema B - Capacitação dos profissionais de saúde.

Discurso do Sujeito Coletivo: médico, enfermeiro e agentes capacitados pra atender o povo, e que o povo também respeitasse os profissionais, por que já vi muitos deles reclamando e os agentes também reclamam que o pessoal não escuta eles (...); capacitação dos agentes de saúde para atendimento domiciliar facilitando o acesso do paciente ao serviço de saúde (...); capacitação de técnicos indígenas para que junto a médicos e enfermeiros desenvolvam um trabalho de atendimento, facilitando a comunicação entre a equipe, incentivos para os próprios indígenas para a formação em saúde, inclusive médicos índios e enfermeiros indígenas também.

Os discursos enfatizam o desejo dos indígenas serem assistidos por profissionais de saúde com formação diferenciada, articulando os saberes científicos e populares no desenvolvimento de propostas e ações de saúde, embasadas no diagnóstico epidemiológico e social da realidade de saúde desse grupo, sem desrespeitar seus princípios culturais e crenças.

É imprescindível que o homem se despoje do seu egocentrismo aniquilador, arme-se de sentimentos de solidariedade e compaixão pelo outro, para que se reacenda a chama dos valores humanos de viver e conviver em coletividade, em defesa da dignidade humana, do respeito à vida, do planeta e valorização das culturas ${ }^{(17)}$.

Assim, os expostos propõem a mudança no processo político gerencial, com a introdução de tecnologias de gestão que proporcionem a identificação de problemas e necessidades de saúde em uma perspectiva social e epidemiologicamente orientada, na busca do favorecimento da ocorrência de mudanças nas práticas de saúde desenvolvidas nas aldeias e problematização das propostas de construção do subsistema de atenção à saúde Pankararu.

Neste sentido, merece aprofundar o debate sobre as propostas alternativas que vêm sendo elaboradas e experimentadas no sentido de construir um modelo que garanta o respeito à equidade, definido em uma concepção que não se limite à garantia da assistência apenas curativa, e sim assegure a integralidade da atenção à saúde e sua promoção ${ }^{(3)}$.

É evidenciado o interesse crescente dos profissionais de saúde pela ampliação do foco dos cuidados na área, para além do estado físico, elegendo a qualidade de vida como um construto que investiga estados subjetivos de satisfação das pessoas em seu viver diário. Essa atitude incorpora o princípio da integralidade como uma dimensão do cuidar ${ }^{(18)}$.

Cabe, portanto, investir em capacitações, oficinas, estudos antropológicos, que favoreçam uma relação de proximidade e confiança entre os profissionais e a comunidade, fortalecendo as equipes multidisciplinares que atuam nas aldeias, para que possam figurar como agentes de transformação, na busca da melhoria da qualidade de vida e autonomia dos povos indígenas.

É proposta, dessa forma, a desenvoltura das redes de atenção, aliadas ao controle social, para que desenvolvam ações em saúde vinculadas às necessidades percebidas e vivenciadas pela população indígena e que garantam ainda a sustentabilidade dos processos de intervenção nos determinantes e condicionantes de saúde, visando à melhoria da qualidade de vida no coletivo.

Emerge a necessidade de deslocar a atenção em uma perspectiva restrita ao adoecimento e sintomas, para o acolhimento integral do indivíduo, observando histórias, condições de vida, e necessidades em saúde, respeitando e considerando as especificidades e as potencialidades na construção dos projetos e na organização do trabalho sanitário nas comunidades Pankararu ${ }^{(15)}$.

\section{Tema C - Acesso às informações}

Discurso do Sujeito Coletivo: (...) e que o índio também recebesse informação nas escolas e nas comunidades (...), que os mais velhos recebessem visita em casa pra ver como tá e tivesse mais organização quando precisasse ir pra Recife porque tem muita gente que vai e não sabe $o$ que fazer quando vai pela primeira vez (...); levantamento estatístico de todas as pessoas que sofrem com doenças crônicas, como o diabetes, hipertensão, dentro da área, principalmente das pessoas mais idosas, dessa forma facilitaria o acompanhamento desses pacientes pelos agentes de saúde, inclusive na distribuição de remédio e dos tratamentos que não podem ser interrompidos (...); promover campanhas sobre DST, controle de natalidade, AIDS, alcoolismo, etc., dentro das escolas, diretamente para adolescentes e também para a comunidade; organizar um calendário para consultas, divididos por idade, tipo de doença, por área, com exceção para as emergências. (...)

Os discursos revelam uma carência, quanto ao acesso aos conhecimentos em saúde, dificultando, aos indígenas, a atuação como sujeitos nas ações de promoção à saúde, mediante o autocuidado e a defesa das necessidades e interesses da coletividade. 
Os Distritos Sanitários Especiais Indígenas deveriam extrapolar os limites dessas unidades articulando ações intersetoriais de promoção à saúde, atividades de educação e comunicação social, voltadas para o fortalecimento da consciência acerca dos direitos sanitários. Contribuindo assim para o engajamento de estratégias de proteção à saúde, bem como, esforços de reorganização na oferta de ações básicas. Na perspectiva epidemiológica, são identificadas algumas aceleradas transformações, marcadas por elevados índices de morbidades crônicas não transmissíveis como, hipertensão e diabetes mellitus, que vêm ao longo do tempo crescendo no coletivo indígena.

As condições de marginalização sócio-econômica vivenciadas pela comunidade Pankararu, tendem a ampliar os impactos sobre o perfil saúde/doença dos indígenas, considerando a enorme diversidade sociocultural, os contrastes e as desigualdades da situação de saúde dessas comunidades em relação a outros segmentos da sociedade. Dessa forma, a promoção à saúde coloca-se como ponte entre o abismo que separa os índios dos modelos de atenção oferecidos a eles, mostrando-se extremamente importante na busca de uma atenção integral e diferenciada com equidade, integralidade e igualdade que hoje não condizem com a realidade vivenciada por esse grupo étnico.

Tradicionalmente, as ações educativas em saúde foram abordadas numa perspectiva individualizante e fragmentária, conduzindo a oferta de receitas e imposições de condutas de saúde sem considerar as expectativas e interesses da comunidade $^{(19)}$.

O regimento legal que delega sobre o processo de trabalho das equipes de atenção básica, aponta para a educação em saúde como ferramenta essencial para uma proposta de ação em saúde com participação popular ${ }^{(20)}$. Faz-se necessário, que os profissionais de saúde estejam sensibilizados com a importância do trabalho com grupos e vivenciem uma abordagem de ensino participativa e libertária, desempenhando atividades de educador, de modo a ensinar e aprender ao mesmo tempo, participando e incentivando as possibilidades de mudanças necessárias, para que o cuidado à vida se faça presente nas situações de saúde e de doença.

Vale ressaltar também uma discussão sobre a Política Nacional de Promoção da Saúde que estabelece entre as macroprioridades do Pacto em Defesa da Vida, o aprimoramento do acesso e da qualidade dos serviços prestados no SUS, com ênfase no fortalecimento e na qualificação estratégica da Saúde da Família; a promoção, informação e educação em saúde com ênfase na promoção de atividade física, na promoção de hábitos saudáveis de alimentação e vida, controle do tabagismo; controle do uso abusivo de bebida alcoólica; e cuidados especiais voltados ao processo de envelhecimento ${ }^{(15)}$.

No SUS, a estratégia de promoção da saúde é retomada como uma possibilidade de enfocar os aspectos que determinam o processo saúde-adoecimento em nosso país, como por exemplo: violência, desemprego, subemprego, falta de saneamento básico, habitação inadequada e/ou ausente, dificuldade de acesso à educação, fome, urbanização desordenada, qualidade do ar e da água ameaçada e deteriorada; e que potencializam formas mais amplas de intervir em saúde ${ }^{(15)}$. Esse entendimento vem redirecionar o olhar dos profissionais de saúde para a abrangência dos temas que merecem constituir o centro das discussões com os grupos da comunidade, nos círculos de educação em saúde ${ }^{(19)}$.

Uma ação educativa, comprometida com a conscientização e mobilização popular, possibilita aos indígenas, não apenas a percepção e também a adoção de comportamentos saudáveis, mas, principalmente, o conhecimento acerca dos direitos em saúde, interagindo de forma mais autônoma na busca de alternativas para o enfrentamento dos seus problemas.

\section{CONSIDERAÇÕES FINAIS}

A partir da análise dos Discursos do Sujeito Coletivo, que é um instrumento imprescindível para identificar os aspectos mais importantes das representações sociais, o estudo evidenciou que a saúde do povo Pankararu passa por sérios problemas, como a falta de organização no atendimento das necessidades de saúde da comunidade, com pouca resolutividade e total descontinuidade nas ações de atenção à saúde e fragilidade nas relações de vínculo dos profissionais com a comunidade; não se observa uma assistência humanizada continuada e integral das ações de saúde, ausência de planejamento participativo local, controle social e promoção à saúde em seu real significado. Além de carência no acesso às informações acerca das patologias que prevalecem na comunidade, modos de contágio e/ou fatores desencadeantes, medidas de prevenção e tratamento; e ainda escassez de medicamentos essenciais no tratamento de doenças crônicas, e desvalorização de práticas de cura da cultura indígena.

A promoção da saúde na comunidade indígena Pankararu necessita do desenvolvimento de ações integradas e articuladas ao comportamento dos mesmos, focado em seu ambiente cultural diferenciado, seu estilo de vida e a relação entre eles e o meio ambiente. Nesse caso, os programas ou atividades de promoção da saúde tendem a concentrarem-se em componentes educativos, que propiciem a disseminação de conhecimento científico articulado ao saber popular, instrumentalizando os profissionais de saúde e a população na identificação e priorização dos problemas de saúde, como também no levantamento de propostas para sua resolução.

Dentre as ações de saúde necessárias para a sua promoção, foram destacadas: o cadastramento dos indígenas portadores de doenças crônicas, para garantia do acompanhamento e tratamento adequado; ações de educação em saúde para a comunidade; contratação de equipe multidisciplinar disposta a trabalhar diariamente com dedicação exclusiva, para eliminar os desnecessários deslocamentos para a cidade em busca de consultas e tratamentos de competência dos serviços de atenção básica; capacitação dos agentes de saúde indígenas para atendimento domiciliar. Foi ressaltada também, a necessidade de formação de profissionais de saúde com competência para estabelecer uma boa relação interpessoal respeitando seus costumes e cultura, como também, assegurar o retorno dos indígenas com formação em saúde para atuarem junto ao seu povo. 
Após inegáveis conquistas na ótica jurídica legal em que se consolidaram a atenção à saúde dos povos indígenas, coloca-se como questão central a reformulação das organizações e estabelecimentos dos subsistemas na promoção à saúde indígena. Para que se possam criar as condições necessárias de forma permanente e sólida, é essencial que o sistema de saúde atual tenha alicerce nas ações de promoção da saúde, tornando-se mais humano, permanente, e, sobretudo, mais resolutivo. Deve ser garantido ainda, que princípios como territorialidade, vínculo, continuidade, planejamento local e promoção à saúde estejam cada vez mais presentes nas pautas das reuniões propostas por movimentos indígenas ligados aos setores de defesa e formulação de políticas públicas para a saúde indígena.

\section{REFERÊNCIAS}

1. Mendes EV. Uma agenda para a saúde. 2 ed. São Paulo: Hucitec; 2006.

2. Ministério da Saúde (Brasil). Secretaria de Políticas de Saúde. Projeto promoção da saúde. Brasília: Ministério da saúde; 2001.

3. Czeresnia C, Freitas CM, organizadores. Promoção da Saúde: conceitos, reflexões, tendências. Rio de Janeiro: Fiocruz; 2003.

4. Coimbra JR, Alvares CE, Santos RV. Health, minorities and inequality: some webs of inter-relations, emphasizing indigenous peoples in Brazil. Ciênc Saúde Coletiva 2000;5(1):125-32.

5. Krieger N. Does racism harm health? Did child abuse exist before 1962? On explicit questions, critical science, and current controversies: an ecosocial perspective. Am J Public Health 2003;93:194-9.

6. Ministério da Saúde (Brasil). Decreto $n^{\circ}$. 3.156, de 27 de Agosto de 1999. Dispõe sobre as condições para a prestação de assistência à saúde dos povos indígenas, no âmbito do Sistema Único de Saúde, pelo Ministério da Saúde. Diário Oficial da União 28 ago 1999.

7. Ministério da saúde (Brasil). Lei nº. 9.836, de 23 de setembro de 1999. Acrescenta dispositivos à Lei $n^{\circ} 8.080$, de 19 de setembro de 1990, que "dispõe sobre as condições para a promoção, proteção e recuperação da saúde, a organização e o funcionamento dos serviços correspondentes e dá outras providências", instituindo o Subsistema de Atenção à Saúde Indígena. Diário Oficial da União 24 ago 1999.

8. Kalipeni E. Health and disease in southern Africa: a comparative and vulnerability perspective. Soc Sci Med [periódico na Internet]. 2000 Abr [acesso em 11 nov 2001];50(7/8) Disponível em <http://www.sciencedirect.com/science $>$.

9. Athias R. Sexualidade, fecundidade e programas de saúde entre os Pankararu. In: Scott P, Athias R, Quadros MT, organizadores. Saúde, Sexualidade e Famílias Urbanas, Rurais e Indígenas. Recife: Editora Universitária UFPE; 2007.

10. Lefèvre AMC, Lefèvre $F$, Cardoso MRL, Mazza MMPR. Assistência pública à saúde no Brasil: estudo de seis ancoragens. Rev Saúde Soc [periódico na internet] 2002; [acesso em 10 jan 2008]2(11) Disponível em: <http:// www.apsp.org.br/saudesociedade/XI_2/assistencia_publica.htm > .

11. Ministério da Saúde (Brasil), Conselho Nacional de Saúde. Resolução nº. 304/2000, de 9 de agosto de 2000. Regulamentação complementar a Resolução 196/96, no que diz respeito à área temática especial "populações indígenas". Diário Oficial da União 9 ago 2000.

12. Silva KL, Sena RR, Grillo MJC, Horta NC, Prado PMC. Educação em enfermagem e os desafios para a promoção de saúde. Rev Bras Enferm 2009;62(1):86-91.

13. Melo LP, Cabral ERM, Junior JAS. O Processo saúde-doença: Uma Reflexão à Luz da Antropologia da Saúde. Rev Enferm UFPE Online 2009;3(4):426-32.

14. Queiroz MS. Saúde e doença: um enfoque antropológico. Bauru: EDUSC; 2003.

15. Ministério da Saúde (Brasil). Portaria nº 687 MS/GM, de 30 de março de 2006. Aprova a Política Nacional de Promoção a Saúde. Diário Oficial da União 30 mar 2006.

16. Marques GQ, Lima MADS. As tecnologias leves como orientadoras dos processos de trabalho em serviços de saúde. Rev Gaúch Enferm 2004;25(1):17-25.

17. Monteiro EMLM, Rolim KMC, Machado MFAS, Moreira RVO. A visão ecológica: uma teia na enfermagem. Rev Bras Enferm 2005;58(3):341-4.

18. Machado MFAS, Monteiro EMLM, Queiroz DT, Vieira NFC, Barroso MGT. Integralidade, formação de saúde, educação em saúde e as propostas do SUS: uma revisão conceitual. Ciência Saúde Coletiva 2007; 12(2):335-42.

19. Monteiro EMLM, Vieira NFC. (Re) Construção de ações de educação em saúde a partir de círculos de cultura: experiência participativa com enfermeiras do PSF do Recife-PE. Recife: EDUPE; 2008.

20. Ministério da Saúde (Brasil). Portaria $n^{\circ} 648$, de 28 de março de 2006: Aprova a Política Nacional de Atenção Básica, estabelecendo a revisão de diretrizes e normas para a organização da Atenção Básica para o Programa Saúde da Família (PSF) e o Programa Agentes Comunitários de Saúde (PACS). Diário Oficial da União 29 mar 2006. 